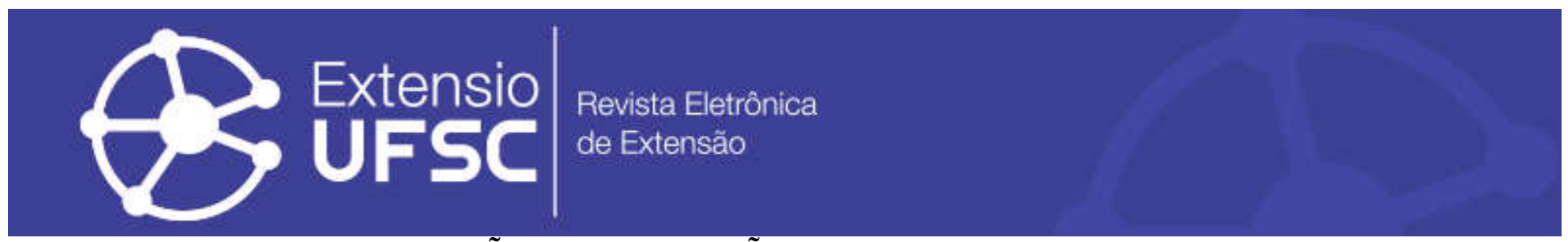

\title{
AVALIAÇÃO DA EXECUÇÃO DO PROGRAMA NACIONAL DE ALIMENTAÇÃO ESCOLAR EM MUNICÍPIOS DO TOCANTINS
}

\author{
Joviana Coelho Afonso \\ Universidade Federal do Tocantins \\ jovianaestudante@gmail.com \\ Leane de Sousa Santos \\ Universidade Federal do Tocantins \\ leane_santos@mail.uft.edu.br
}

\author{
Claudia Jaqueline Fialho \\ Universidade Federal do Tocantins \\ claudiajf@mail.uft.edu.br \\ Juciléia Maria Casali \\ Universidade Federal do Tocantins \\ jucileiamariacasali@gmail.com \\ Luciana Pereira Jacobsen \\ Universidade Federal do Tocantins \\ lucianapereirajacobsen@gmail.com
}

Resumo

O Programa Nacional de Alimentação Escolar visa fornecer uma alimentação adequada e saudável aos estudantes. Objetivou-se avaliar a execução do Programa Nacional de Alimentação Escolar em 26 municípios do Tocantins no ano de 2018, com base na Lei $n^{\circ} 11.947$, de 16 de junho de 2009. Trata-se de um estudo descritivo-quantitativo, a partir das atividades e questionários aplicados com atores envolvidos no programa, os questionários foram elaborados pelo Fundo Nacional de Desenvolvimento da Educação e aplicados pelas agentes do Centro Colaborador em Alimentação e Nutrição Escolar da Universidade Federal do Tocantins. Os relatórios gerados foram disponibilizados para o estudo, onde foram analisados os seguintes aspectos: possui nutricionista, realiza chamada pública, atinge os 30\% destinados à Agricultura Familiar, possui saldo em conta superior a 30\%, realiza atividades de Educação Alimentar Nutricional,se o Conselho de Alimentação Escolar é ativo e atuante. Portanto, é importante demonstrar a magnitude do programa.

Palavras-chave: Alimentação Escolar. Agricultura Familiar. Nutricionista. Conselho de Alimentação Escolar.

\section{EVALUATION OF EXECUTION OF THE NATIONAL SCHOOL NUTRITION PROGRAM IN DISTRICTS OF THE TOCANTINS}

Abstract

The National School Nutrition Program, which aims to provide adequate and healthy food to students. The goal of this study was to examine the execution of the program in 26 districts of the state of Tocantins in 2018, based on Law $\mathrm{n}^{\circ}$ 11,947 of June 16th, 2009. This is a descriptive-quantitative study, starting of activities and questionnaires administered to actors involved in the program. The questionnaires were designed by the National Fund for Educational Development and administered by agents from the Federal University of Tocantins Collaborating Center for School Food and Nutrition. The reports produced were made available to the study, in which the presence or not of the following features were analyzed: existence of a nutritionist, setting of a public bidding, observance of the $30 \%$ quota for the Family Farming, existence of an account balance over 30\%, performance of Food and Nutrition Educational Activities, existence and effectiveness of a School Feeding Council. Therefore, it is important to demonstrate the magnitude of the program.

Keywords: School Nutrition. Family Farming. Nutritionist. School Feeding Council.

\section{AVALIACIÓN DE EJECUCIÓN DEL PROGRAMA NACIONAL DE ALIMENTACIÓN ESCOLAR EM MUNICÍPIOS DE TOCANTINS}

\section{Resumen}

El Programa Nacional de Alimentación Escolar visa proporcionar una alimentación adecuada saludable a los estudiantes. Objetivado evaluar la ejecución del programa en 26 municípios del Tocantins em el año de 2018, com base em la Ley $\mathrm{n}^{\circ}$ 11.947, de 16 de junio de 2009. Se trata de um estudio descritivo-cuantitativo, a partir de las actividades y cuestionários aplicados com actores involucrados en programa, los cuestionários fueron elaborados por el Fondo Nacional de Desarrollo de la Educación y aplicados por agentes del Centro Colaborativo em Alimentación y Nutrición Escolar de la Universidad Federal del Tocantins. Los informes generados se pusieron a disposición para el estudio, donde analizaron los seguientes aspectos: tiene nutricionista, realiza llamada pública, atinge los 30\%, realiza atividades de educación alimentar nutricional, si el consejo nacional de alimentación escolar es activo y actuante. Por lo tanto, es importante demostrar la magnitude del programa.

Palavras clave: Alimentación Escolar. Agricultura Familiar. Nutricionista. Consejo de Alimentación Escolar. 
Avaliação da execução do programa nacional de alimentação escolar em municípios do Tocantins

\section{INTRODUÇÃO}

O Programa Nacional de Alimentação Escolar (PNAE) é um programa do Ministério da Educação, que tem como objetivo contribuir para o crescimento e o desenvolvimento biopsicossocial, a aprendizagem, o rendimento escolar e a formação de hábitos alimentares saudáveis dos alunos, por meio de ações de educação alimentar e nutricional e da oferta de refeições que cubram as suas necessidades nutricionais durante o período letivo (BRASIL, 2009).

É um dos programas públicos mais abrangentes na área da alimentação e de Segurança Alimentar e Nutricional (SAN), sendo capaz de comandar um atendimento universal aos escolares e garantir a alimentação adequada e saudável, efetivando as demandas dos Direitos Humanos (BRASIL, 2015).

O PNAE tem como meta atender todos os alunos cadastrados no censo escolar, englobando todas as modalidades de ensino e entidades filantrópicas. Atualmente o Programa é gerenciado pelo Fundo Nacional de Desenvolvimento da Educação (FNDE), objetivando melhorias das condições nutricionais, contribuição para a aprendizagem, rendimento do escolar e a formação de hábitos alimentares saudáveis, segundo a Lei no 11.947/2009 (BRASIL, 2019).

O FNDE também é o responsável por realizar os repasses financeiros para as entidades executoras responsáveis pela execução do programa. As quantidades de recursos transferidos são de acordo com o censo escolar realizado no ano anterior e esse valor deve atender as demandas da agricultura familiar. Visto isso, a Resolução no 26, de 17 de junho de 2013, enfatiza que a entidade executora é responsável por fazer a prestação de contas do programa ao órgão que a delegou (BRASIL, 2013).

Desde sua implantação, o PNAE passou por diversas modificações em sua estrutura, dentre elas, a extinção da centralização em que um órgão gerenciador planejava os cardápios e estes eram responsáveis por fornecer os alimentos em todo o território nacional. No entanto, a Lei $n^{\circ}$ 8.913/1994 estabeleceu a descentralização dos recursos para a execução do programa, porém, a consolidação desse processo só foi possível a partir da Medida Provisória nº1.784/1998, sob o comando do FNDE (BRASIL, 2017).

Segundo Santos, Costa e Bandeira (2016), a descentralização foi de suma importância, pois, a compra dos gêneros alimentícios passou a contemplar os alimentos regionais e, sobretudo, aqueles produzidos pela agricultura local, proporcionando um cardápio de acordo com os hábitos alimentares locais. Para Balestrin, Fung e Sudbrack (2016), o processo de descentralização possibilitou a participação e controle da sociedade no processo de decisões em relação à gestão 
Avaliação da execução do programa nacional de alimentação escolar em municípios do Tocantins

pública por meio do Conselho de Alimentação Escolar (CAE), que é um órgão de caráter fiscalizador e de assessoria.

A gestão descentralizada conta com a participação do FNDE e das Entidades Executoras, o primeiro, por sua vez, é a autarquia responsável por realizar os cálculos financeiros dos valores a serem repassadas para as Entidades Executoras, que são as secretarias de educação municipais, as escolas estaduais e federaisencarregadas de efetuar as demandas do PNAE, de acordo com o que é determinado pela Legislação no $11.947 / 2009$. É importante ressaltar que a transferência ocorre de forma automática (BRASIL, 2015).

Nessa perspectiva, visando aperfeiçoar e garantir as demandas do PNAE, foi instituída a Lei $n^{\circ}$ 8.913, de 12 de julho de 1994, que estabelece a inserção do nutricionista no programa. Essa Lei, em seu artigo $4^{\circ}$, dispõe que: a elaboração dos cardápios dos programas de alimentação escolar, sob a responsabilidade dos Estados e Municípios, ocorre através de nutricionista capacitado respeitando os hábitos alimentares de cada localidade e sua vocação agrícola (BRASIL, 1994).

Ademais, a Lei $\mathrm{n}^{\circ}$ 11.947, de 16 de junho de 2009, estabelece que a responsabilidade técnica pela alimentação escolar nos Estados, no Distrito Federal, nos Municípios e nas escolas federais é do nutricionista, e a Resolução CD/FNDE no 26, de 17 de junho de 2013, complementa que este deve ser, obrigatoriamente, vinculado ao setor de alimentação escolar da Entidade Executora (BRASIL, 2018).

A Resolução do Conselho Federal de Nutricionistas - CFN n 465/2010, atualizou as atribuições previstas na rotina desse profissional. Visto isso, cabe ao nutricionista acompanhar o estado nutricional dos estudantes, planejar, elaborar e acompanhar o cardápio da alimentação escolar, desde a aquisição dos alimentos, preparo e fornecimento aos alunos, considerando os aspectos culturais, coordenar e elaborar as ações de educação alimentar e nutricional, juntamente com o grupo pedagógico da escola (BRASIL, 2019).

Nesse cenário, é visível que o programa em questão possui atributos necessários para conceder uma alimentação saudável, tornando-se uma das políticas estratégicas para a promoção da saúde. Diante do atual cenário alimentar e nutricional do país, Prado et al. (2016), definiu que as ações de Educação Alimentar e Nutricional (EAN) são fontes de habilidades para a promoção da saúde. Logo, as ações de EAN devem buscar apoios pedagógicos e educacionais, trabalhando não só com a alimentação do aluno, mas, com todos os atores envolvidos com o PNAE. Sob tal enfoque, observa-se a necessidade de o nutricionista sempre executar ações de EAN, pois estará proporcionando uma alimentação adequada, de acordo com os princípios do PNAE. 
Avaliação da execução do programa nacional de alimentação escolar em municípios do Tocantins

Visando auxiliar no controle e na gestão do PNAE, foram criados em 2006 os Centros Colaboradores de Alimentação Escolar (CECANE), em parceria com o FNDE e as instituições federais de ensino, através da Portaria Interministerial $\mathrm{n}^{\circ}$ 1.010, de 8 de maio de 2006. Os CECANEs são unidades capazes de desenvolver ações referentes ao PNAE, principalmente prestar assessoria aos atores sociais envolvidos com o programa como, por exemplo, manipuladores de alimentos, os conselheiros da alimentação escolar, agricultores familiares, nutricionistas e outros (BRASIL, 2017).

No ano de 2018, os Agentes do Centro Colaborador de Alimentação Escolar da Universidade Federal do Tocantins (CECANE/UFT) realizaram assessorias em 26 municípios do estado do Tocantins, visando melhorias na qualidade da alimentação escolar e, principalmente, garantir a efetividade do Programa Nacional de Alimentação Escolar. Durante cada visita foram abordadas falhas na execução do programa, as quais englobaram vários pontos: as escolas estavam adquirindo produtos sem selo de inspeção, o CAE não enviava os pareceres conclusivos de anos anteriores, incluindo também o não atingimento da meta de 30\% advindos da agricultura familiar e até mesmo a ausência da compra. O FNDE, juntamente com o CECANE, tem o objetivo de corrigir essas falhas através dos planos de ação. Tais planos são baseados em portarias, notas técnicas e legislações, oferecendo a forma adequada de execução do PNAE.

Este estudo teve como objetivo avaliar a execução do Programa Nacional de Alimentação Escolar (PNAE) nas escolas municipais de 26 municípios do Tocantins, com base na Lei $\mathrm{n}^{\circ}$ 11.947, de 16 de junho de 2009.

\section{METODOLOGIA}

Trata-se de um estudo descritivo com abordagem quantitativa, com base nas atividades e questionários aplicados com os atores envolvidos no PNAE em vinte e seis municípios do estado do Tocantins, nos meses de março a agosto de 2018. Os dados foram obtidos a partir de assessorias aos municípios e os questionários estruturados foram elaborados pelo FNDE e aplicados pelos nutricionistas Agentes do CECANE/UFT.

Os relatórios gerados de cada município foram disponibilizados para a realização do presente estudo, dos quais foram analisados os seguintes aspectos: possuía nutricionista responsável técnico, realizou processo de chamada pública para aquisição de produtos da agricultura familiar, atingiu os $30 \%$ destinados à compra de produtos oriundos da agricultura familiar, tinha saldo em conta superior a 30\%, realizou atividades de EAN nas escolas, se o CAE 
Avaliação da execução do programa nacional de alimentação escolar em municípios do Tocantins

era ativo diante do FNDE e se era atuante. Os dados foram tabulados no Excel, de acordo com a situação de cada município e posteriormente gerado um gráfico para análise de números.

Os municípios foram previamente selecionados, de acordo com os seguintes critérios estabelecidos pelo FNDE: ausência de compra da agricultura familiar, prestação de contas não enviadas, possuir saldo acima de 30\% em conta do PNAE e demanda oriunda de órgãos de controle ou casos de denúncias. É importante ressaltar que, dentre os vinte e seis municípios, somente dois apresentavam gestão positiva para o FNDE. Os critérios que determinam uma gestão positiva se verificam quando o município atinge todas as metas do programa e tem investimento na alimentação escolar maior do que a contrapartida enviada pelo FNDE.

Durante as visitas foram realizadas reuniões com gestores, CAE, nutricionistas, agricultores familiares e setor financeiro. Em cada encontro foi elaborado um plano de ação, no qual foram descritas as ações corretivas (erros identificados, setor ou ator social responsável pela ação, orientação segunda a legislação sobre a execução e prazo para a execução das ações corretivas) para cada município.

\section{RESULTADOS E DISCUSSÃO}

Dos municípios selecionados, 23,07\% estão localizados na microrregião de Araguaína, 19,23\% na microrregião do Jalapão, 15,38\% na microrregião do Bico do Papagaio, assim como, na de Rio Formoso, as microrregiões de Miracema do Tocantins, Gurupi e Dianópolis contaram $\operatorname{com} 7,7 \%$, respectivamente, e a microrregião de Porto Nacional com apenas 3,8\%.

Durante a avaliação dos critérios de seleção estabelecidos pelo FNDE, foi diagnosticado que nove municípios não conseguiram atingir os 30\% dos repasses destinados à agricultura familiar e seis municípios não realizaram a compra de produtos oriundos da agricultura familiar, portanto, estes foram os critérios que obtiveram maior índice de inadimplência entre os demais.

Outro critério que obteve destaque, diz respeito ao CAE, o qual deixou pendências, não enviando os pareceres conclusivos de anos anteriores, sendo que cinco municípios foram diagnosticados com a gestão negativa por não realizarem este processo. Destes municípios, durante a assessoria, dois já se encontravam devidamente regularizados pela gestão vigente no ano de 2018.

Quatro municípios limitavam-se a algum dos seguintes itens: saldo superior ao determinado em conta, aquisição de produtos sem selo de inspeção, falta de apoio técnico e controle da parte financeira. 
Avaliação da execução do programa nacional de alimentação escolar em municípios do Tocantins

Quanto aos dois municípios com gestão positiva, os quesitos avaliados são contraditórios, visto que um destes não realizou chamada pública e ambos não atingem a meta de $30 \% \mathrm{em}$ compras de alimentos da agricultura familiar.

Os resultados apresentados são referentes aos critérios de seleção estabelecidos pelo FNDE (Tabela 1).

Tabela 1 - Critérios de seleção estabelecidos pelo FNDE e o número de municípios que se enquadram nesses critérios.

Critério de seleção $\quad$ Número de municípios

Não atingiu os 30\% destinados à agricultura familiar 9

Ausência na compra de produtos da agricultura familiar 6

O CAE não enviou os pareceres conclusivos dos anos anteriores 5

Saldo superior ao determinado em conta 1

Aquisição de produtos sem selo de inspeção 1

Falta de apoio técnico 1

Falta de controle da parte financeira 1

\begin{tabular}{ll} 
Municípios com gestão positiva & 2 \\
\hline
\end{tabular}

Total 26

Fonte: FNDE/CECANE/UFT

De acordo com os resultados obtidos, foi possível verificar que o nutricionista estava presente em vinte e quatro municípios e ausente em dois. Sendo que desses dois municípios havia um nutricionista contratado para efetuar as demandas do programa, no entanto, a mesmo não se fazia presente havia mais de seis meses e, no outro município, foi constatado que não existia nutricionista para atuar no programa. Tais resultados estão em desacordo com a Lei $\mathrm{n}^{\circ}$ 11.947/2009, que determina que o nutricionista é o responsável técnico pela alimentação escolar, e a Resolução CD/FNDE n 26/2013, que complementa que este deve ser, obrigatoriamente, vinculado ao setor de alimentação escolar da Entidade Executora.

Segundo a Resolução do CFN nº 465/2010, é necessário um nutricionista responsável técnico, atuando em 30 horas semanais para atender até 500 alunos. No entanto, apesar do nutricionista estar presente em grande parte dos municípios tocantinenses, está em desacordo com a resolução, pois, atende um número de alunos superior ao estabelecido ou cumpre carga horária inferior da preconizada em lei.

Os resultados encontrados são semelhantes à pesquisa realizada por Silva et al. (2018), onde foram analisados 214 municípios no estado de Goiás. Em tal estudo, foi possível verificar que em 26,2\% dos municípios seria necessário mais um nutricionista, por atenderem de 501 a 1.000 estudantes, enquanto os demais deveriam contar com mais dois nutricionistas. Nesse 
Avaliação da execução do programa nacional de alimentação escolar em municípios do Tocantins

mesmo estudo, os profissionais relataram que a carga horária de trabalho está inferior à regulamentada em lei.

Souza et al. (2017) avaliou a atuação de 77 nutricionistas em municípios de Minas Gerais e Espírito Santo, onde foi possível detectar que a carga horária média de trabalho era de 25 horas. Metade desses profissionais afirmaram a falta de outro nutricionista para compor o quadro técnico, quando o número de alunos ultrapassa de 500. Dessa forma, é notório que este gargalo persiste em outras regiões do país e que abre espaços para outras irregularidades.

Corrêa et al. (2017) ressalta que o nutricionista é o responsável por promover hábitos alimentares saudáveis os quais influenciarão na saúde do alunado, assumindo no PNAE atribuições como a elaboração de cardápios associado à compra de alimentos da agricultura familiar, realizando o acompanhamento da compra dos gêneros alimentícios, elaborando e realizando ações de EAN, assim como, assessorando o CAE no que diz respeito à execução técnica e, além disso, incentivando o conselho a participar ou formar reuniões com os agricultores familiares para facilitar a aquisição de alimentos.

Souza et al. (2017) subtende que os profissionais, quando são contratados pelas entidades executoras, apresentam incertezas no emprego e isso pode impossibilitar a autonomia do nutricionista em exercer o seu trabalho como recomendado em lei. Tal problemática está presente no estado do Tocantins, onde foi verificado que em vinte e cinco municípios, o nutricionista exerce sua função através de contratos temporários. Nesse sentido, tornou-se evidente que a ausência de autonomia deste profissional afeta diretamente os outros setores do PNAE como agricultura familiar, CAE, ações de EAN - e que serão trabalhados neste estudo todos de suma importância para a efetividade do programa e para a alimentação saudável dos usuários.

A agricultura familiar oferece ao alunado produtos seguros e saudáveis, respeitando a cultura local por levar em consideração a sazonalidade e a quantidade do produto disponível na região. Dessa forma, o nutricionista é capaz de criar um cardápio nutricionalmente adequado e com produtos de qualidade (BRASIL, 2015).

Diante dos dados obtidos, verificou-se que vinte e um municípios não conseguiram atingir 30\% dos repasses com a agricultura familiar e apenas três municípios alcançaram ou ultrapassaram este valor (Gráfico 1). O resultado encontrado neste item supera o quantitativo de municípios que foram definidos pelo FNDE, por estarem irregulares quanto a este critério. Tal resultado, contrapõe a Lei no $11.947 / 2009$, a qual tem como meta estabelecer uma alimentação saudável para os alunos de escolas públicas e estimular a agricultura familiar nacional. É determinado pelo FNDE que no mínimo 30\% do valor repassado aos estados e municípios 
Avaliação da execução do programa nacional de alimentação escolar em municípios do Tocantins

devem ser destinados ao PNAE, sendo utilizados obrigatoriamente na compra de gêneros alimentícios provenientes da agricultura familiar.

De acordo com Rodrigues et al. (2017), um município do Espírito Santo, no ano de 2014, utilizou um valor maior do que o repassado pelo FNDE, 116,68\% foram destinados a compra de produtos oriundos deste meio, realidade diferente dos municípios tocantinenses, que pode estar relacionada com a falta de articulação dos gestores com os produtores.

Nessa perspectiva, foram diagnosticadas durante a obtenção dos dados algumas dificuldades que impossibilitam o cumprimento da meta de 30\%, destinado à agricultura familiar como altos preços dos produtos, inviabilidade de fornecimento regular e constante dos gêneros alimentícios conforme o cronograma, condições higiênico-sanitárias inadequadas, articulação entre os atores e elaboração do projeto de venda.

O processo de chamada pública não foi realizado em seis municípios, sendo este um fator negativo e preocupante, visto que, o fato de não haver chamada pública corrobora com o alto índice de municípios que não atingem o limite mínimo de 30\% de aquisição de alimentos da agricultura familiar (Gráfico 1). A Resolução CD/FNDE nº 26/2013 determina que a entidade executora que dispensar os processos licitatórios, estabelecidos na Lei 11.947/2009, deverá ter a aquisição de produtos alimentícios concedidos pela chamada pública. Os editais de chamadas públicas devem ser divulgados em todos os meios de comunicação local e os gêneros alimentícios que serão entregues são definidos na mesma.

Nesse cenário, foi possível identificar que os vinte e um municípios que não conseguiram atingir os 30\% destinados à agricultura familiar não utilizaram os recursos de forma satisfatória, ou seja, o saldo pode ter sido utilizado para a compra de outros gêneros. A Resolução $n^{\circ} 26$ de junho de 2013, enfatizou que os municípios podem contribuir com recursos financeiros próprios para assegurar que a oferta da alimentação nas escolas se dê em conformidade com as necessidades nutricionais dos alunos, inclusive complementando a aquisição de gêneros alimentícios, caso necessário. Visto isso, os vinte e seis municípios analisados participaram com recurso próprio, com pelo menos a compra da alimentação escolar nos meses de janeiro e fevereiro, meses os quais a Entidade Executora não recebeu repasse do FNDE. 
Avaliação da execução do programa nacional de alimentação escolar em municípios do Tocantins

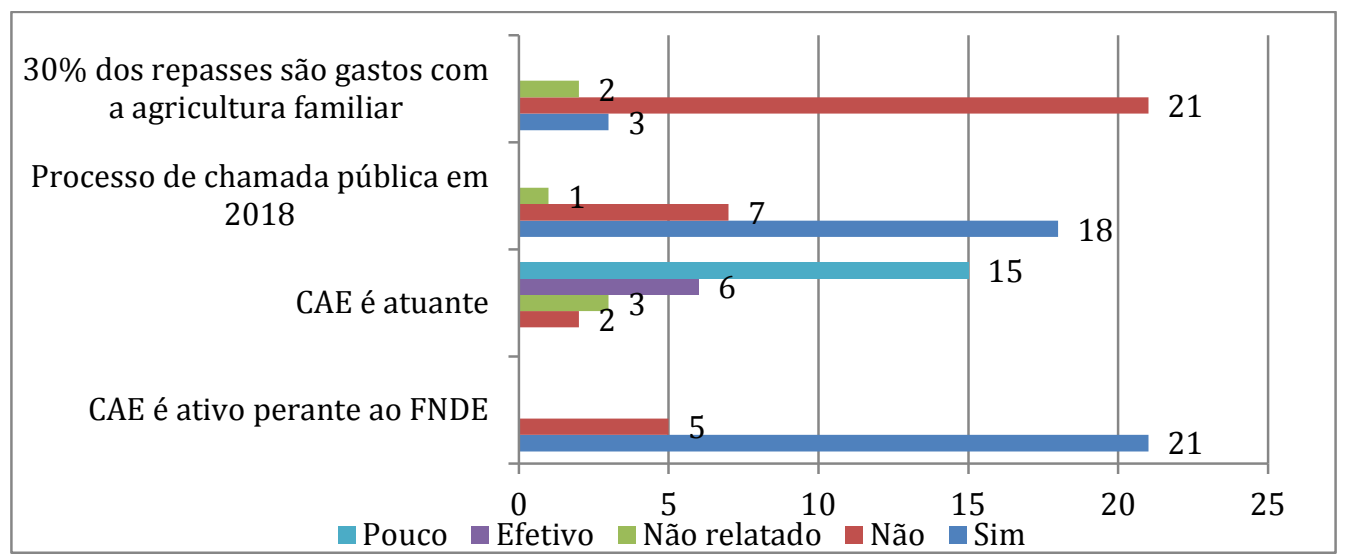

Gráfico 1 -Situação da Agricultura Familiar e do Conselho de Alimentação Escolar (CAE). Fonte: FNDE/CECANE/UFT.

De acordo com os regulamentos da Lei no $11.947 / 2009$, é proibido ao município armazenar em conta recursos financeiros acima de 30\% oriundos do FNDE. Nesse sentido, foi possível observar dois municípios irregulares e em um dos municípios verificou-se que a gestão da alimentação não estava especificando a fonte do recurso do FNDE, apenas fonte própria, por sua vez, o outro município apresentava saldo superior em conta em decorrênciados recursos advindos do Programa Mais Educação, o qual não era utilizado e com o passar do tempo essa quantia ficou bloqueada na conta. Nesse sentido, é de suma importância que os municípios entrem em contato com o FNDE, a fim de esclarecer os eventuais erros e regularizar a situação.

É válido mencionar que o CAE fiscaliza a execução do PNAE dentro do município. Sua atuação foi regulamentada pela Lei no 11.947/2009 e pela Resolução n 26/2013 do FNDE. Também é importante salientar que os conselheiros devem observar as aplicações dos recursos públicos destinados ao programa, acompanhar a aquisição dos alimentos, a qualidade da alimentação ofertada, as condições de preparação dos alimentos e as atividades de EAN (BRASIL, 2017).

De acordo com a análise dos dados, foi verificado que em vinte e um municípios o conselho estava ativo perante ao FNDE e apenas cinco inativos (Gráfico 1). No entanto, esses dados são contraditórios, pois em apenas seis municípios as ações do CAE eram efetivas desde as visitas nas escolas, acompanhamento da aplicação dos recursos, participação na aquisição de gêneros alimentícios e envio do parecer conclusivo para o FNDE. Vale ressaltar que apesar de serem efetivos os conselhos necessitavam elaborar relatórios de todas as atividades realizadas, visitar as escolas com frequência, receber orientações e esclarecimento de dúvidas com auxílio do nutricionista. No estudo realizado por Gabriel, Goulart e Calvo (2015), em que avaliou a atuação do CAE nas três capitais da região Sul do país, verificou-se um resultado regular para duas capitais e um ruim, nesse sentido é visível que os dados não diferem muito. 
Avaliação da execução do programa nacional de alimentação escolar em municípios do Tocantins

Bosquilia e Pipitone (2019) destacam a importância e a abrangência do CAE perante o PNAE e enfatiza que a forma dos conselheiros trabalharem pode refletir em um mau funcionamento do programa. Nesse tocante e através da observação realizada, nota-se que em quinze municípios tocantinenses o CAE é pouco atuante e isso ocorre devido a não prestação de contas, inexistência de visitas nas escolas, na aquisição de produtos alimentícios entre outros fatores.

A inatividade do CAE proporciona aspectos negativos à agricultura familiar, às ações de EAN e a todos os atores sociais que participam do PNAE. Castro (2018) define que o CAE deve zelar pela qualidade da alimentação oferecida para os alunos da rede pública de ensino.

As ações de EAN são de suma importância na rede de ensino. Esta prática deve abordar recursos educacionais, de modo que atenda e favoreça os grupos e indivíduos, pois por meio dessas ações é possível promover hábitos alimentares saudáveis nas escolas levando em consideração todas as fases do ciclo da vida. A EAN objetiva estimular a adoção voluntária de práticas e escolhas alimentares saudáveis que colaborem para a aprendizagem, a boa saúde do escolar e a qualidade de vida do indivíduo. (FNDE, 2019).

A falta de EAN leva o aluno a fazer escolhas alimentares inadequadas, na maioria das vezes consomem em excesso produtos ultraprocessados, sem saber o que está comendo de fato. Essa prática alimentar pode acarretar em problemas de saúde a longo ou curto prazo, doenças crônicas como: hipertensão, diabetes, obesidade, entre outras (PATRIOTA, 2018).

O ideal seria que todas as escolas oferecessem ações de EAN, porém, os dados obtidos mostram que oito municípios não realizaram tais ações, enquanto 18 executaram. Embora seja menor o número de municípios que não aderiram àEAN, o resultado é insatisfatório, pois o PNAE tem a finalidade de atingir a totalidade de ações no âmbito escolar (Gráfico 2).

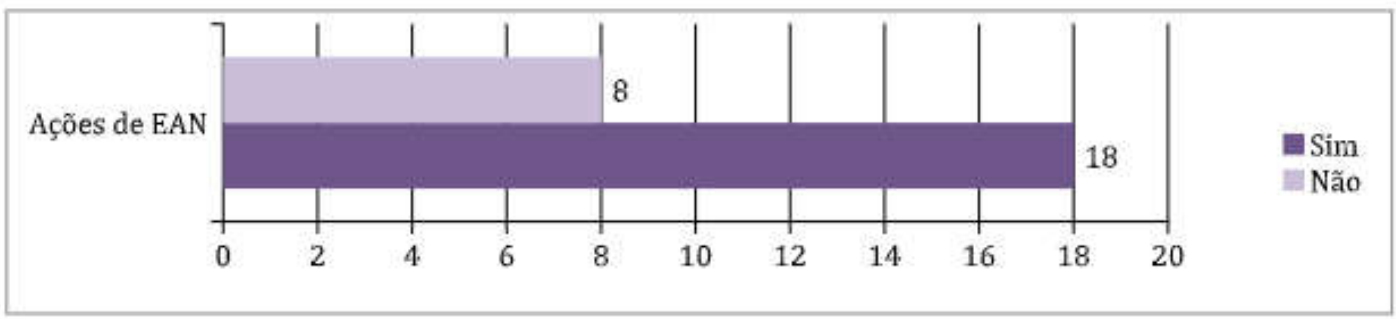

Gráfico 2 - Execução das ações de Educação Alimentar e Nutricional (EAN). Fonte: FNDE/CECANE/UFT.

De acordo com os dados obtidos, foi possível verificar que vinte e cinco municípios possuem gestão centralizada e apenas um adota a gestão descentralizada. Para Santos, Costa e Bandeira (2016), ambas as formas são capazes de gerar os recursos de forma exata. Além dessas 
Avaliação da execução do programa nacional de alimentação escolar em municípios do Tocantins

formas de gestão, tem-se ainda a semidescentralizada e a terceirizada, estas, por sua vez, não estão presentes nos municípios do Tocantins.

De acordo com Ferreira, Alves e Melo (2019), a gestão descentralizada possibilita maior facilidade com a aquisição de produtos regionais, sobretudo, valoriza a agricultura familiar. Neste modelo a escola é a responsável pela compra dos alimentos. Nesse contexto, verifica-se que apesar de um município possuir gestão descentralizada, o mesmo não consegue atingir o mínimo de $30 \%$ dos repasses destinados ao produtor familiar.

Foi possível identificar que a forma de gestão mais adotada pelos municípios é a centralizada, para Belik e Chaim (2009) um dos motivos que levam a entidade executora a adotar esse modelo é o fato de possibilitar um controle mais eficaz do processo de operacionalização do programa, além disso, confere um maior poder de negociação da entidade executora com os fornecedores. Segundo Ferreira, Alves e Melo (2019), esse modelo de gestão permite que as entidades executoras, ou seja, as secretarias de educação recebam as verbas destinadas ao PNAE, as mesmas são responsáveis pela compra e distribuição dos alimentos nas escolas. Para Santos, Costa e Bandeira (2016), uma das vantagens da centralização é que os gêneros alimentícios podem ser comprados por um valor mais baixo devido ao grande volume comprado.

A fim de estabelecer orientações sobre o que deve ser melhorado na execução do PNAE, foram elaborados planos de ações, compostos por cinco vertentes (o quê, quem, quando, onde e justificativa), facilitando o planejamento e acompanhamento das atividades. O principal objetivo é estabelecer ações necessárias para que a meta seja atingida, além de definir o responsável pela realização de cada atividade e estabelecer prazos para o cumprimento da mesma. Desse modo, é possível possibilitar que a entidade executora com os atores sociais siga uma sequência de tarefas previamente delimitadas pelo profissional responsável, levando àconcretização dos objetivos de forma mais rápida, prática e segura (Quadro 1).

\begin{tabular}{|c|c|c|c|c|}
\hline O que? & Quem? & Quando? & Onde? & Justificativa? \\
\hline $\begin{array}{c}\text { Contratação de } \\
\text { um } \\
\text { nutricionista } \\
\text { com no } \\
\text { mínimo 30 } \\
\text { horas semanais }\end{array}$ & Prefeitura & Imediatamente & $\begin{array}{c}\text { Secretaria de } \\
\text { educação }\end{array}$ & $\begin{array}{c}\text { Resolução CFN } \\
465 / 2010 .\end{array}$ \\
\hline $\begin{array}{c}\text { Participar do } \\
\text { processo de } \\
\text { compra de } \\
\text { alimentos e } \\
\text { chamadas } \\
\text { públicas }\end{array}$ & Nutricionista & $\begin{array}{c}\text { Conforme a } \\
\text { demanda }\end{array}$ & A definir & $\begin{array}{c}\text { Ter ciência dos } \\
\text { alimentos } \\
\text { comprados. }\end{array}$ \\
\hline
\end{tabular}


Avaliação da execução do programa nacional de alimentação escolar em municípios do Tocantins

\begin{tabular}{|c|c|c|c|c|}
\hline $\begin{array}{c}\text { Realizar } \\
\text { atividades de } \\
\text { educação } \\
\text { nutricional nas } \\
\text { escolas. }\end{array}$ & Nutricionista & $\begin{array}{l}\text { No mínimo uma } \\
\text { vez por } \\
\text { semestre }\end{array}$ & Escolas & $\begin{array}{c}\text { Construção e } \\
\text { promoção de hábitos } \\
\text { saudáveis. }\end{array}$ \\
\hline $\begin{array}{l}\text { Visitas nas } \\
\text { escolas } \\
\text { municipais. }\end{array}$ & CAE & Imediatamente & Escolas & $\begin{array}{c}\text { Cartilha Nacional de } \\
\text { Alimentação Escolar, } \\
2^{\circ} \text { edição, Brasília, } \\
2015 .\end{array}$ \\
\hline $\begin{array}{c}\text { Elaborar } \\
\text { relatórios das } \\
\text { atividades. }\end{array}$ & CAE & Imediatamente & $\begin{array}{l}\text { Sala de } \\
\text { reuniões }\end{array}$ & $\begin{array}{c}\text { Devem ser } \\
\text { documentadas todas } \\
\text { e quaisquer atividade } \\
\text { realizada pelo } \\
\text { conselho para o } \\
\text { cumprimento do Art. } \\
\text { 35, da Resolução } \\
\text { CD/FNDE } 26 \text {, de } \\
\text { junho de } 2017 .\end{array}$ \\
\hline $\begin{array}{c}\text { Elaborar } \\
\text { justificativa da } \\
\text { presença de } \\
\text { saldo maior que } \\
30 \% \text { em conta. }\end{array}$ & $\begin{array}{l}\text { Entidade } \\
\text { executora }\end{array}$ & Imediatamente & $\begin{array}{c}\text { Secretaria de } \\
\text { Educação }\end{array}$ & $\begin{array}{c}\text { Evitar o } \\
\text { cancelamento de } \\
\text { recurso advindo do } \\
\text { FNDE. }\end{array}$ \\
\hline
\end{tabular}

Quadro 1 - Plano de ação - Planejamento das atividades a serem corrigidas pelos municípios que não tiveram gestão positiva.

Fonte: FNDE/CECANE-UFT

\section{CONSIDERAÇÕES FINAIS}

Esse trabalho possibilitou entender como funciona o PNAE em cada município, com suas dificuldades e demandas específicas de cada ator social responsável pela execução do mesmo. Os dados aqui apresentados mostram a necessidade do fortalecimento na execução das atribuições do PNAE e para isso é fundamental que haja o estreitamento dos laços entre órgãos fiscalizadores e entidades executoras, agindo em conjunto para que possa de forma significativa garantir as demandas do programa preconizadas na Lei 11. 947/2009. Além disso, é esperado que este estudo venha despertar nos gestores reflexões para a efetiva concordância do programa, visando garantir uma alimentação de qualidade para os escolares. 
Avaliação da execução do programa nacional de alimentação escolar em municípios do Tocantins

\section{REFERÊNCIAS}

BAESTRIN, M.; FUNG, H.S.; SUDBRACK, E.M. As políticas públicas brasileiras de alimentação escolar: da centralização à descentralização - do assistencialismo à participação popular. Integra Educativa. v. 9, n. 1, p.141-157, 2016.

BELIK, W.; CHAIM, N.B. O programa nacional de alimentação escolar e a gestão municipal: eficiência administrativa, controle social e desenvolvimento local. Revista de Nutrição, Campinas, v. 22, n. 5, p. 595- 607, 2009.

BOSQUILIA, S.G.C.C; PIPITONE, M.A.P. A importância da Soberania Alimentar no âmbito do Conselho de Alimentação Escolar no município de Piracicaba (SP). Segurança Alimentar e Nutricional, Campinas, v. 26, p. 1-8, 2019.

BRASIL. Lei $\mathbf{n}^{\mathbf{0}}$. 8.913, de 12 de julho de 1994. Dispõe sobre a municipalização da merenda escolar. Diário Oficial da União, 1994.

BRASIL. Ministério da Saúde. Gabinete do Ministro. Portaria no 1.399, de 08 de maio de 2006. Brasília, 2006.

BRASIL. Resolução/CD/FNDE n $^{\circ} 38$ de 16 de julho de 2009. Dispõe sobre o atendimento da alimentação escolar aos alunos da educação básica no Programa Nacional de Alimentação Escolar (PNAE). Diário Oficial da União, 2009.

BRASIL. Lei $\mathbf{n}^{\circ}$ 11.947, de 16 de junho de 2009. Dispõe sobre o atendimento da alimentação escolar e do Programa Dinheiro Direto na Escola aos alunos da educação básica. Diário Oficial da União 17 jun. 2009.

BRASIL. Fundo Nacional de Desenvolvimento da Educação. Resolução CD/FNDE $\mathbf{n}^{\mathbf{o}}$ 26/2013. Dispõe sobre o atendimento da alimentação escolar aos alunos da educação básica no âmbito do Programa Nacional de Alimentação Escolar - PNAE. Brasília, 2013.

BRASIL. Ministério da Educação. Fundo Nacional de Desenvolvimento da Educação. Cartilha Nacional da Alimentação Escolar. Brasília, DF: $2^{a}$ ed., 2015, 88p.

BRASIL. Ministério da Educação. Fundo Nacional de Desenvolvimento da Educação. Aquisição de produtos da agricultura familiar para a alimentação escolar. Brasília, DF: $2^{\mathrm{a}}$ ed., 2015, 32p.

BRASIL. Tribunal de Contas da União. Cartilha para conselheiros do Programa Nacional de Alimentação Escolar (PNAE). Brasília, DF, p. 119, 2017.

BRASIL. Ministério da Educação. Fundo Nacional de Desenvolvimento da Educação ou Programa Nacional de Alimentação Escolar. Histórico. Brasília, 2017. Disponível em: https://www.fnde.gov.br/index.php/programas/pnae/pnae-sobre-o-programa/pnae-historico Acesso em: 18 de maio de 2019.

BRASIL.Ministério da Educação. Fundo Nacional de Desenvolvimento da Educação. Nutricionistas do PNAE Manual de apoio para as atividades técnicas do nutricionista no âmbito do PNAE. Brasília, DF, 2018, 106p. 
Avaliação da execução do programa nacional de alimentação escolar em municípios do Tocantins

BRASIL. Fundo Nacional de Desenvolvimento da Educação. Ministério da Educação. Programa Nacional de Alimentação Escolar - PNAE. Caderno de Legislações 2019. Atualizado em 09 de abril de 2019.

BRASIL. Ministério da Educação. Fundo Nacional de Desenvolvimento da Educação. Educação Alimentar e Nutricional - EAN, Brasília, 2017. Disponível em: https://www.fnde.gov.br/programas/pnae/pnae-eixos-de-atuacao/pnae-educacao-alimentarnutricional. Acesso em: 17 de nov. de 2019.

CASTRO, R. Educação alimentar e nutricional enquanto processo educativo: um estudo de práticas e percepções de uma comunidade escolar de Uberaba-MG. Temas em Educação e Saúde, Araraquara, v. 14, n. 2, p. 215-228, jul./dez., 2018.

CFN. CONSELHO FEDERAL DE NUTRICIONISTAS. Resolução nº 465, de 23/08/2010. Dispõe sobre as atribuições do Nutricionista, e estabelece parâmetros numéricos mínimos de referência no âmbito do PNAE e dá outras providências. Brasil, 2010.

CORRÊA, R. S. et al. Atuação do Nutricionista no Programa Nacional de Alimentação Escolar na Região Sul do Brasil. Ciência \& Saúde Coletiva, v. 22, n. 2, p. 563-574, Rio de Janeiro, fev. 2017.

FERREIRA, H.G.R; ALVES, R.G; MELLO, S.C.R.P. O Programa Nacional de Alimentação Escolar (PNAE): alimentação e aprendizagem. Revista da Seção Judiciária do Rio de Janeiro, [S.1.], v. 22, n. 44, p. 90-113, abr. 2019. ISSN 2177-8337.

GABRIEL, C.G.; GOULART, G.; CALVO, M.C.M. Gestão municipal do Programa Nacional de Alimentação Escolar nas capitais da região Sul do Brasil. Revista de Nutrição, Campinas, v. 28, n.6, p.667-680, nov./dez., 2015

PATRIOTA, P. Alimentos ultraprocessados: como afetam a saúde. Centro de Recuperação e Educação Nutricional, São Paulo, 2018. Disponível em: http://www.cren.org.br/blog/2018/05/17/alimentos-ultraprocessados. Acesso em: 17 de nov. de 2019

PRADO, B.G. et al. Ações de educação alimentar e nutricional para escolares: um relato de experiência.Demetra: alimentação, nutrição e saúde, v. 11, n. 2, p. 369-382, Rio de Janeiro, 2016.

RODRIGUES, R. et al. A aquisição de alimentos da agricultura familiar pelo PNAE no município de Alegre-ES. Demetra: alimentação, nutrição e saúde, v. 12, n. 1, p. 91-112, Rio de Janeiro, 2017.

SANTOS, S.R; COSTA, M.B.S; BANDEIRA, G.T.P. As formas de gestão do Programa Nacional de Alimentação Escolar (PNAE). Revista Salud Pública, v. 18, n. 2, p. 311-322, Bogotá: Colômbia, 2016.

SILVA, S.U. et al. As ações de educação alimentar e nutricional e o nutricionista no âmbito do Programa Nacional de Alimentação Escolar. Ciência \& Saúde Coletiva, v. 23, n. 8, p. 2671 2681, Rio de Janeiro, 2018. 
Avaliação da execução do programa nacional de alimentação escolar em municípios do Tocantins

SOUZA, A.A. et al. Atuação de nutricionistas responsáveis técnicos pela alimentação escolar de municípios de Minas Gerais e Espírito Santo. Ciência \& Saúde Coletiva, v. 22, n. 2, p. 593 606, Rio de Janeiro, 2017.

Recebido em: 16/03/2020

Aceito em: 08/03/2021 